brings his own experience, and his treatment of them is particularly valuable.

The book, which is an English translation and expansion of an earlier German edition, is beautifully illustrated and is full of inspiration for future workers. There is a section, regrettably brief, on the phylogeny of the order and its taxonomic position. Weygoldt questions the traditional connexion with the true scorpions, hints at possible relations with the Uropygi, and demonstrates the resemblance to the Solifugae. This is followed by an outline classification, which helpfully correlates the differences in nomenclature used by earlier writers. The bibliography, largely confined to publications of the past twenty years, is comprehensive and valuable.

Apart from its intrinsic merits, this book carries a significance that should be mentioned. It appears at a time when a large-scale work on scorpions is in preparation in Paris, and a new edition of The Biology of Spiders is taking shape, whon the Ricinulei are beginning to reveal some of their mysteries, and the Opiliones are being intensively studied in America. Taken together, these activities presage a lively and growing interest in the Class Arachnida, which may well be destined to make a notable contribution to zoology in the decade of tho seventies.

THEODORE SAVORY

\section{FOSSIL SEX}

\section{Sexual Dimorphism in Fossil Metazoa and Taxonomic Implications}

Edited by G. E. G. Westermann. (International Union of Geological Sciences, Series A, Number 1.) Pp. iv +250 . (E. Schweizerbart'sche Verlagsbuchhandlung (Nägele u. Obermiller); Stuttgart, 1969.) DM 46; \$12.30.

SoME readers might suppose that a paperback containing discussions of "sex symbols" (p. 154), unattainable "ideals" (p. 119), incitement to violate "the Rules" (p. 119), "palaeopornography" (p. 244) and quotations from a Quaker pamphlet (p. 242) needs only a lurid cover to guarantce it a conspicuous place on the shadier newstands. Others, who habitually savour a book by reading the final line first, may be disappointed that the volume is scarcely the "Iight-hearted and rewarding" study that one of its authors elaims it to be. The aim of Dr Westermann's timely volume is more restricted: it is to assemble data on sexual dimorphism in fossil metazoans, and to consider their taxonornic implications. Though overly concerned with cophalopods, tho papers represent a significant contribution to palaeontological theory and practice. The volume grew out of a symposium planned for the ill-fated August 1968 Prague meeting of the International Geological Congress.

The volume contains a brief review of the biological foundations of sexuality ("a device for promoting genotic variability and adaptation") which contains a particularly useful discussion of the interaction of environment and inheritance in a number of species. Two short papers discuss mathematical techniques (goneralized statistical distance calculations and polydimensional decision matrix methods) for recognition of sexual dimorphism. Eighty per cent of the book (200 pages of the book's 250) is taken up with detailed studies of sexual dimorphism (or lack of it) in various fossil groups. These papers involve three on brachiopods (one recognizing sexual dimorphism, a second not recognizing it, and a third being agnostic), nine on molluses (six of them on cephalopods), three on arthropods, one on echinoderms and two on vertebrates. Almost all these papers lack the statistical sophistication urged by the writers in the introductory biometric papers, but they contain studies of a great variety of such apparently dimorphic characters as alar extensions in brachiopods, subtle differences in shape, convexity, marginal crenulation and ornament in pelecypods, size and ornament in cephalopods, eyes in trilobites, genital opercular appen- dages and ornament in eurypterids, genital pores and plates in echinoids and the more familiar skeletal features of vertebrates. The papers on Palaeocene Astarte by Kauffman and Buddenhagen and on the Namurian trilobite Weberides by Clarkson are particularly elegant examples of the interpretation of sexual dimorphism. Most of the papers are followed by short discussions, revealing various degrees of polite scepticism at some of the interpretations, and a profound degree of difference concerning the taxonomic treatment of dimorphism in fossils. One school of thought, vigorously championed by J.H. Calloman, one of the fathers of the 1963 ammonite sexual revolution, opts for a morphological classification ("objective, practical, stable, flexible, no presuppositions") which would accord analogous sexual features different "taxonomic rank according solely to their morphological complexity" (p. 116), but would generally use the subgeneric level for that purpose.

"If such a morphological taxonomy violates . . . the Rules, so much the worse for the Rules. . . . [It would] provide the grammar of a powerful language, one that still allows experts to disagree, but disagrce precisely" (pp. 119-120).

The other taxonornic school, though lacking a champion of such robust, rousing verbal challenges, advocates the use of standard neontological practice ("natural, objective, phylogenetic, simple"), which demands that sexual dimorphs be assigned to the same biospecies, but distinguished by the usual male and female symbols. There is no final agreement in this (is there ever in palaeon. tology ?), though a short, impartial, benevolent, magisterial note by R. E. Blackwelder advocates tho adequacy of the existing rules and predicts the final triumph of justice, law and order (represented by the second school). Most readers will agree with Blackwelder's verdict and share his hopes, though whether all the authors of the symposium will is quite another matter.

The present collection of essays contains no discussion of the evolution of sexual dimorphism, of the selective value and development of scxual characters, or of palaeopopulation dynamics-all of which represent exciting potential outgrowths of the topic. As such, it raises far more problems than it solves. And that, perhaps, is the highest function that any such symposium can perform.

F. H. T. RHODES

\section{LIFE IN THE FLY BELTS}

\section{Africa's Bane}

The Tsetse Fly. By T. A. M. Nash. Pp. $224+8$ plates. (Collins: London. February 1970.) 42s.

ALtнобgh Dr Nash warns specialists they will learn nothing from his book, they will certainly be interested in this first attempt, and there is no other, to give an account of the tsetse problem as a whole by one of the chief exponents of the entomological control of trypanosomiasis.

In 1930, two papers appeared in the Bulletin of Entomo. logical Research, one by Nash and the other by C. H. N. Jackson. Both were working in Tanzania but far apart from one another and, perhaps because both were directed by that remarkable naturalist, C. F. M. Swynnerton, their conclusions had much in common. They led to a general theory of tsetse behaviour, especially of Glossina morsitans, which provided a foundation for control schemes which is still in use, even though bush clearing and wildlife destruction have largely been superseded by insecticides. At the academic level, this theory remained unassailed until 1960 and it has not yet been replaced. Jackson contributed much to the techniques of population estimation, but Nash remaincd more the entomologist, intent on the individual insect. One observes that, of these two forty year old papers, that by Nash is most in accord with recent physiological and ethological findings. The main fault with the idea of "the feeding ground" lies in the 